THÉMATA. Revista de Filosofía

$\mathrm{N}^{\circ} 49$, Enero-junio (2014) pp.: 33-50

ISSN: 0212-8365 e-ISSN: 2253-900X

doi: 10.12795/themata.2014.i49.02

\title{
LA CONFRONTACIÓN CON EL ESPÍRITU: KANDINSKY Y WITTGENSTEIN REVELAN QUÉ ES LO QUE CONMUEVE EN EL GRAN ARTE
}

\author{
THE CONFRONTATION WITH THE SPIRIT: KANDINSKY AND \\ WITTGENSTEIN REVEAL WHAT MOVES IN GREAT ART
}

\author{
José María Ariso ${ }^{1}$ \\ Universidad Internacional de la Rioja (España)
}

Recibido: 05-07-2012

Aceptado: 17-01-2013

\begin{abstract}
Resumen: En este artículo pretendo mostrar en qué coinciden las opiniones de Kandinsky y Wittgenstein respecto al importantísimo papel que el espíritu juega en el modo en que las grandes obras de arte nos conmueven. Partiendo de este paso previo, señalaré las profundas diferencias que subyacen en las concepciones que tanto Kandinsky como Wittgenstein tenían del espíritu y, por extensión, de la conmoción artística. Pues la concepción que Kandinsky tenía del arte estaba muy estrechamente relacionada con el teosofismo, mientras que Wittgenstein contemplaba la verdadera obra de arte como el fruto de una vida religiosa.
\end{abstract}

Palabras-clave: Espíritu, arte, naturaleza, autoconocimiento, religión.

\begin{abstract}
In this paper, I hope to clarify the main similarities between Kandinsky's and Wittgenstein's opinions on the very important role that the spirit plays in the way great works of art move us. Basing myself on this previous step, I will emphasize the deep differences which underlie the conceptions Kandinsky and Wittgenstein had of the spirit and, by extension, of artistic commotion. For Kandinsky's notion of art was very closely related to theosophism, while Wittgenstein considered the authentic work of art as the result of a religious life.
\end{abstract}

Key-words: Spirit, art, nature, self-knowledge, religion.

[1] (josemaria.ariso@unir.net) José María Ariso se doctoró en Psicología por la Universidad Complutense de Madrid en 2003 y desde 2011 es profesor adjunto en la Universidad Internacional de la Rioja. Ha disfrutado de estancias como investigador y profesor invitado en diversas universidades extranjeras. Sus principales líneas de investigación son la Teoría del Conocimiento, la Filosofía de la Educación, la Filosofía de la Psiquiatría, la filosofía española contemporánea y la obra de Ludwig Wittgenstein. 


\section{Introducción}

No debería extrañarnos que muchas personas se vieran desconcertadas si se les preguntara por las similitudes o puntos de contacto existentes entre las concepciones que del arte tenían Wassily Kandinsky y Ludwig Wittgenstein. De hecho, parece haber argumentos de peso para justificar dicha perplejidad. En lo que respecta al pintor ruso, es sobradamente conocido que sus principales objetivos tanto en De lo espiritual en el arte ${ }^{2}$ como en El jinete azul ${ }^{3}$, el famoso almanaque que coeditó con Franz Marc, eran aclarar en qué consistiría el arte monumental que debía surgir de la unión de las distintas artes y, por encima de todo, despertar la capacidad de captar lo espiritual en las cosas materiales y abstractas. Con este fin, en De lo espiritual en el arte se pueden encontrar ya múltiples observaciones sobre el lenguaje de formas y colores que constituye la pintura ${ }^{4}$, mientras que en la obra que según el propio Kandinsky constituye su «continuación orgánica» ${ }^{5}$, Punto y línea sobre el plano, se va a centrar en el análisis del punto, la línea y el plano básico. En lo que toca a Wittgenstein, no hace falta decir que no fue un artista sino un filósofo con una gran sensibilidad artística, especialmente musical, que abordó múltiples temas entre los que se hallan la estética y el arte. Así, en su Tractatus logico-philosophicus va a relegar a la ética y a la estética, a las que considera una y la misma cosa ${ }^{6}$, al ámbito de lo místico e inefable, pues en la concepción del mundo que se desarrolla en el Tractatus no hay cabida para hechos éticos o estéticos. Sin embargo, con el paso de los años Wittgenstein dejará de tratar la estética como una consideración sub specie aeternitatis de las cosas y ya en sus "Lecciones de estética»", impartidas durante el verano de 1938, se dedicará a analizar diversos aspectos de su gramática, lo cual le llevará a expresarse constantemente en términos de juicios, explicaciones, descripciones y reacciones estéticas. A esto hay que añadir una serie de observaciones dispersas y enigmáticas que Wittgenstein hizo en relación con el arte -por ejemplo, respecto a los distintos papeles que juega el arte en la cultura y en la civilización-, observaciones que aparecen sobre todo en la compilación de aforismos que lleva por título Cultura y valor ${ }^{8}$. A

[2] Kandinsky, W.: De lo espiritual en el arte. Barcelona: Labor, 1995.

[3] Kandinsky, W. y Marc, F. (eds.). El jinete azul. Barcelona: Paidós, 1989.

[4] No obstante, la exposición más detallada de los estudios de Kandinsky sobre las formas y los colores se halla en los textos que elaboró para preparar sus clases en la Bauhaus de Weimar. Ver Kandinsky, W.: Cursos de la Bauhaus. Madrid: Alianza, 1991.

[5] Kandinsky, W.: Punto y línea sobre el plano. Contribución al análisis de los elementos pictóricos. Barcelona: Labor, 1995, p. 8.

[6] Wittgenstein, L.: Tractatus logico-philosophicus. Barcelona: Altaya, 1994, § 6.421.

[7] Cfr. Wittgenstein, L.: Lecciones y conversaciones sobre estética, psicología y creencia religiosa. Barcelona: Paidós, 1996, pp. 63-108.

[8] Wittgenstein, L.: Cultura y valor. Aforismos. Madrid: Austral, 1996, §§ 25, 27-29, 40, 103, 120,

THÉMATA. Revista de Filosofía, Nº49 enero-junio (2014) pp.: 33-50

doi: 10.12795/themata.2014.i49.02 
tenor de lo dicho, cabe preguntarse qué podrían tener en común Kandinsky, el pintor del que se ha afirmado hasta la saciedad que tenía como fin último pintar la música, y Wittgenstein, el filósofo empeñado en analizar la estética como si de un juego de lenguaje más se tratara. En el presente artículo me propongo mostrar que esta interpretación de la concepción que ambos autores tenían del arte y la estética es sumamente superficial, pues no hace justicia a la importancia que concedieron a la confrontación con el espíritu dentro del proceso de creación artística. Pero si bien es cierto que Kandinsky y Wittgenstein coinciden al poner un gran énfasis en la participación en el espíritu, sus respectivas concepciones de lo espiritual difieren en grado sumo. Pues tal y como pretendo mostrar en este trabajo, Kandinsky entiende el espíritu en estrecha relación con el teosofismo que tan de moda estaba entre los artistas a finales del siglo XIX y comienzos del XX, mientras que Wittgenstein concibe la participación en el espíritu desde una perspectiva religiosa basada en la humillación ante Dios y la fidelidad a la naturaleza propia de cada cual. En este punto me gustaría hacer un breve inciso para dejar claro que me voy a centrar en observaciones que Wittgenstein escribió durante sus últimos veinte años de vida, haciendo especial hincapié en sus diarios del año 1937. Con esto quiero decir que no entraré a analizar la concepción del "espíritu» que cabe hallar, por ejemplo, en los diarios que Wittgenstein escribió durante su participación en la Primera Guerra Mundial. No obstante, considero que Wittgenstein pretendió a lo largo de toda su vida alcanzar su salvación interior al buscar en el espíritu la libertad que le permitiera independizarse de las contingencias mundanas y vivir una vida justa. De hecho, creo que la noción de fidelidad a la propia "naturaleza» que voy a exponer en este trabajo constituye en buena medida la elaboración posterior de la concepción que en su juventud tuvo Wittgenstein del «espíritu» como principio de la vida auténtica.

Así pues, comenzaré mostrando la fuerte influencia que las enseñanzas teosóficas tuvieron en la concepción del arte -y muy especialmente de la pintura como lenguaje de formas y colores- desarrollada por Kandinsky, para lo cual atenderé no sólo a los textos clásicos o más conocidos del pintor ruso, sino también a sus observaciones y anotaciones relacionadas con cuestiones teosóficas en las que se adivina como telón de fondo el ansia de recuperar la armonía perdida con el universo. Posteriormente me centraré en la confrontación con lo espiritual que Wittgenstein desarrolla como elemento clave de su propia religiosidad, por lo que prestaré especial atención a un texto que aparentemente poco o nada tiene que ver con cuestiones artísticas: me refiero a la compilación de sus diarios que lleva por título Movimientos del pensar ${ }^{9}$. Por último, y

125, 192, 197, 203, 323-324, 335, etc.

[9] Wittgenstein, L.: Movimientos del pensar. Diarios 1930-1932/1936-1937. Valencia: Pre-Textos, 2000 .

THÉMATA. Revista de Filosofía, Nº 49 enero-junio (2014) pp.: 33-50

doi: 10.12795/themata.2014.i49.02 
a modo de conclusión, destacaré los puntos de contacto y de alejamiento que existen en las concepciones de la confrontación con el espíritu mantenidas por Kandinsky y Wittgenstein, pues este sutil contraste debe ayudarnos a entender con especial claridad las concepciones del arte que cabe apreciar en estas dos grandes figuras del pasado siglo XX.

\section{La influencia de la teosofía en la obra de Kandinsky}

Una de las principales ideas que Kandinsky expone en De lo espiritual en el arte es que la obra de arte surge cuando se armoniza el todo sobre el lien$\mathrm{zo}^{10}$. Pues Kandinsky presupone la existencia de un orden cósmico del cual nos ha separado la ciencia y la filosofía: se trata de un orden al que sólo podremos retornar por medio del arte, desarrollando nuestra sensibilidad hasta tal punto que seamos capaces de captar lo espiritual en las cosas materiales y abstractas. Esta captación de lo espiritual es inefable, ya que no puede expresarse en palabras. Según Kandinsky, el lenguaje con el que la naturaleza ejerce su fuerza insuperable sobre nosotros es inimitable ${ }^{11}$, de modo que sólo puede ser captado a nivel meramente intuitivo en forma de sonoridad interna o inherente a cada una de las cosas y combinaciones tanto de formas como de colores que nos rodean ${ }^{12}$. Naturalmente, el mundo sonoro al que se refiere Kandinsky no es el de la sonoridad externa que percibimos a través de nuestro sentido del oído, sino el cosmos de los seres que obran espiritualmente. A juicio del pintor ruso, si los dibujos infantiles nos subyugan tan a menudo es porque los niños todavía son ajenos a lo práctico-utilitario y conservan la capacidad de percibir el sonido interior de cada objeto, lo cual les permite aceptar las cosas tal y como son ${ }^{13}$. Así que cuando Kandinsky escribe que la génesis de una obra de arte es de carácter cósmico, lo que quiere decir es que el creador de la obra es el espíritu: o lo que es lo mismo, la obra existe de forma abstracta antes de ser materializada y resultar accesible a los sentidos. Si el espíritu está ausente, ni la lógica ni la intuición podrán crear obras verdaderamente valiosas ${ }^{14}$. Tanto la lógica como la intuición son meros medios para expresar o dar forma al contenido que el artista quiere -o mucho mejor aún, necesita - transmitir en un momento dado. Para Kandinsky los medios utilizados, sean éstos cuales sean, sólo resultan vá-

[10] Kandinsky, W.: De lo espiritual cit., p. 24.

[11] Ibídem, p. 50.

[12] En opinión de Kandinsky, estamos constantemente expuestos a las «irradiaciones psicológicas» de todos y cada uno de los objetos de nuestro entorno, si bien rara vez somos conscientes de ellas. Ibídem, p. 68.

[13] Kandinsky, W.: «Sobre la cuestión de la forma» en Kandinsky, W. y Marc, F. (eds.): El jinete azul. Barcelona: Paidós, 1989, p. 159.

[14] Kandinsky, W.: "Conferencia de Colonia» en Kandinsky, W.: La gramática de la creación. El futuro de la pintura. Barcelona: Paidós, 1996, p. 52.

THÉMATA. Revista de Filosofía, No 49 enero-junio (2014) pp.: 33-50

doi: 10.12795/themata.2014.i49.02 
lidos - o según su propia expresión, «sagrados»- si brotan de la fuente de lo que él denomina «necesidad interior» ${ }^{15}$. Según el principio básico de la necesidad interior propuesto por Kandinsky, la armonía de los colores debe basarse única y exclusivamente en "el principio del contacto adecuado con el alma humana» ${ }^{16}$. ¿Pero qué quiere decir Kandinsky al utilizar aquí el adjetivo «adecuado»?"${ }^{17}$. La respuesta la hallamos poco después, cuando Kandinsky advierte que la caracterización externa de la forma - o sea, la delimitación de una superficie por otra- es distinta de su caracterización interna -es decir, el contenido interno que cada forma posee y expresa-. Pues bien, de la caracterización externa dice Kandinsky que será "exhaustivamente adecuada» cuando descubra el contenido interno del modo más expresivo ${ }^{18}$. La forma queda así subordinada a la fiel y espontánea manifestación del contenido interno que el artista necesita expresar en un momento dado, de modo que el artista sólo debería trabajar cuando sea guiado por la voz de su necesidad interior. Cuando algo brote de la necesidad interior, dice Kandinsky, poseerá una belleza interna que refinará y enriquecerá el alma ${ }^{19}$. Será entonces cuando el arte contribuya al desarrollo y sensibilización del alma humana, ofreciéndole el alimento espiritual que sólo de ese modo puede recibir: un alimento gracias al cual el alma, lejos de envilecerse, se mantendrá en un tono adecuado tal y como las cuerdas de los instrumentos musicales se mantienen en un tono óptimo gracias al diapasón ${ }^{20}$. Será entonces cuando se restablezca el equilibrio psicológico perdido y se estimule la interioridad del hombre, el cual será dichoso ${ }^{21}$ porque por fin habrá sido partícipe del «sentimiento de lo cósmico» que Kandinsky identifica con la música de las esferas ${ }^{22}$.

La breve exposición que acabo de ofrecer de algunas ideas básicas de la obra escrita de Kandinsky basta para revelar hasta qué punto el pintor ruso era afín a la sensibilidad artística de su tiempo. Al fin y al cabo, a finales del siglo XIX y comienzos del XX estaba ya muy difundida la creencia de que una nueva era espiritual iba a relevar, tomando el arte como punto de partida, al materialismo del siglo XIX: de hecho, Runge ya se había propuesto a comienzos del siglo XIX alcanzar una gran síntesis de las artes y plasmarla en una obra de arte integral. Además, Nietzsche, Maeterlinck y Friedrich habían puesto

[15] Kandinsky, W.: De lo espiritual cit., p. 75.

[16] Ibídem, p. 59.

[17] Ídem.

[18] Ibídem, p. 64.

[19] Ibídem, p. 117.

[20] Ibídem, pp. 23, 114.

[21] Kandinsky, W.: Cursos de la Bauhaus cit., p. 118.

[22] Kandinsky, W.: «El arte de hoy está más vivo que nunca» en Kandinsky, W.: La gramática de la creación. El futuro de la pintura. Barcelona: Paidós, 1996, p. 119.

THÉMATA. Revista de Filosofía, No 49 enero-junio (2014) pp.: 33-50

doi: 10.12795/themata.2014.i49.02 
de moda en el siglo XIX la teoría del origen cósmico del arte, mientras que la idea de la "necesidad interior» ya había sido abordada -si bien con distintas denominaciones- por Schopenhauer, Bergson y el propio Nietzsche. A esto hay que añadir las similitudes existentes entre las ideas de Kandinsky y la teoría del arte romántica, similitudes entre las que cabe destacar la primacía concedida a lo interno frente a lo externo, la creencia de que existe un poder creativo derivado de la identidad interna entre el yo y el cosmos, y la convicción de que una "música interna» -en tanto que sólo es perceptible para un sentido interno- permea la naturaleza. Pero si bien no hay constancia de que Kandinsky estuviera familiarizado con obras románticas, existen pruebas evidentes de que estudió con gran detenimiento múltiples textos teosóficos. Como es sabido, la Sociedad Teosófica (The Theosophical Society) había sido fundada en Nueva York pocos años antes, en 1875, por la Madame rusa Helena Petrovna Blavatsky y el coronel americano Henry Steele Olcott. El principio en torno al cual gira la teosofía es que sólo existe una verdad eterna que le fue dada al hombre al comienzo de su existencia. A pesar de que dicha verdad habría sido adulterada con el paso del tiempo debido a la influencia de corrientes como el positivismo y el materialismo, mantienen los teósofos, permanecería intacta en los misterios y la tradición esotérica de los grandes iniciados, hasta el punto que todas las religiones existentes conservarían ciertos elementos de la verdad primigenia mezclados con impurezas adquiridas con posterioridad. Blavatsky se basa en la imagen del «rayo blanco» de luz pura que habría sido difractada en los distintos colores del espectro para ilustrar cómo la teosofía habría sido descompuesta en las diversas religiones y filosofías. Así pues, la tarea de los teosofistas consistiría en reunir todos los colores que compiten -afirmando ser cada uno de ellos el rayo blanco- en la original y auténtica luz blanca de la verdad. Según Blavatsky, esta síntesis tendría lugar a lo largo del siglo XX, durante el cual la humanidad recobraría gradualmente las facultades clarividentes de las que habría disfrutado en un principio ${ }^{23}$. Dicho esto, a continuación voy a mostrar que, si bien es cierto que Kandinsky perteneció durante toda su vida a la Iglesia Ortodoxa y que -a diferencia de otros artistas como Mondrian- nunca fue miembro de la Sociedad Teosófica, las enseñanzas teosóficas tuvieron una gran influencia en su obra.

El propio Kandinsky manifiesta abiertamente en De lo espiritual en el arte su simpatía hacia Blavatsky y la Sociedad Teosófica, a la que califica como «uno de los más importantes movimientos espirituales» del momento: aunque considera un tanto precipitado el optimismo de los teósofos, matiza que "el amplio movimiento espiritual es real» y añade que se trata de un poderoso agente que trae consigo una "promesa de salvación» para los corazo-

[23] Blavatsky, H. P.: The Key to Theosophy. London: The Theosophical Publishing Company, 1889 , p. 40.

THÉMATA. Revista de Filosofía, No 49 enero-junio (2014) pp.: 33-50

doi: 10.12795/themata.2014.i49.02 
nes desesperados, a los que «indica el camino y ofrece ayuda» ${ }^{24}$. Kandinsky no sólo no muestra reparo alguno al citar The Key to Theosophy de Blavatsky y los artículos de Rudolf Steiner -otro destacado teósofo- sobre los caminos del conocimiento en Lucifer-Gnosis ${ }^{25}$, sino que además adopta la terminología de Blavatsky. Un ejemplo de ello lo encontramos cuando Kandinsky escribe que es el espíritu creador, "el rayo blanco que fecunda», lo que provoca un impulso interior que lleva consciente o inconscientemente a buscar una forma material para la forma espiritual que vive dentro de él, mientras que "la mano negra» -otra expresión teosófica acuñada por Blavatsky- es la fuerza que desde el siglo XIX se opone al rayo blanco por generar miedo a la libertad y sordera ante el espíritu ${ }^{26}$. No obstante, las influencias más claras que Kandinsky recibió de la teosofía fueron apuntadas por Sixten Ringbom ${ }^{27}$. Veamos algunas de ellas. En primer lugar, los comentarios de Kandinsky alabando los beneficios de la cromoterapia -como ejemplo del gran poder que los colores ejercen sobre el cuerpo humano ${ }^{28}$ - se derivan de un tratado de cromoterapia de Arthur Osborn Eaves titulado Die Kräfte der Farben, tal y como lo demuestran las notas que Kandinsky escribió previamente al margen de un volumen de dicha obra ${ }^{29}$. En segundo lugar, la comparación que Kandinsky establece entre el alma y las cuerdas de un piano a las que la naturaleza hace vibrar guarda un estrecho paralelismo con un pasaje de Eaves subrayado por el pintor ruso en el que se lee que toda vida, ya se manifieste como ameba o como hombre, no es sino vibración $^{30}$. En tercer lugar, la abstrusa idea de Kandinsky según la cual toda palabra es un sonido que brota del objeto al que la palabra sirve de nombre ${ }^{31}$ se desarrolló a partir de una técnica que Steiner denominó «percepción de la palabra interna», técnica en la que el poder espiritual de las palabras se manifiesta por medio de la lectura o escucha pasiva ${ }^{32}$. Pero vayamos ya con la influencia que la teosofía ejerció sobre la concepción que Kandinsky tenía del «espíritu». En cuarto lugar, Kandinsky señaló que los objetos y los seres adquieren un sonido interior -el cual constituye la expresión manifiesta del espíritu en

[24] Kandinsky, W.: De lo espiritual cit., pp. 38-40. Cabe preguntarse si el distanciamiento que muestra Kandinsky hacia los teósofos al considerar precipitado su optimismo no podría deberse al incesante afán que siempre mostró por preservar su propia originalidad.

[25] Ibídem, p. 39.

[26] Kandinsky, W.: «Sobre la cuestión» cit., pp. 131-133.

[27] Ringbom, S.: The Sounding Cosmos. A Study in the Spiritualism of Kandinsky and the Genesis of Abstract Painting. Åbo: Åbo Akademi, 1970, pp. 93-118.

[28] Kandinsky, W.: De lo espiritual cit., p. 59.

[29] Eaves, A. O.: Die Kräfte der Farben: der Weg zur Gesundheit. Berlin: Georgi, 1906, p. 8.

[30] Ibídem, p. 34.

[31] Kandinsky, W.: De lo espiritual cit., p. 41.

[32] Steiner, R.: "Wie erlangt man Erkenntnisse der höheren Welten?" en Lucifer-Gnosis, 1904, p. 51.

THÉMATA. Revista de Filosofía, No 49 enero-junio (2014) pp.: 33-50

doi: 10.12795/themata.2014.i49.02 
todo objeto- para quien desarrolla suficientemente su sensibilidad ${ }^{33}$. Esta idea halla su inspiración en la obra de Steiner, según el cual todas las cosas son audibles en su más profunda esencia ${ }^{34}$. Además, Kandinsky subrayó en un libro de Steiner una serie de pasajes en los que éste afirmaba que todo aquello que se percibe como ley, idea, color o luz constituye algo musical para el oído espiritual $^{35}$. En quinto y último lugar, la concepción que tenía Kandinsky de la necesidad interior cuya satisfacción debería ir acercándonos progresivamente a «la época de la gran espiritualidad ${ }^{36}$ es casi idéntica a la doctrina teosofista de la gnosis prístina presente en las religiones y filosofías de todos los tiempos: de acuerdo con esta doctrina, toda religión tiene un significado externo y uno interno, siendo este último núcleo invariable de verdad la teosofía misma que cuando llegue la era espiritual se extenderá entre la humanidad. Así, la "verdad eterna» de Blavatsky tiene su exacta equivalencia en lo que Kandinsky denomina "puro y eternamente artístico» ${ }^{37}$ : mientras que la primera estaría, según Blavatsky, presente en toda religión, el segundo estaría presente, de acuerdo con Kandinsky, en toda obra de arte. Al fin y al cabo, lo «puro y eternamente artístico» constituye para Kandinsky el espíritu mismo, es decir, aquello que realmente conmueve en la obra de arte y que, al igual que la verdad eterna pregonada por Blavatsky, debería alcanzar su máxima expresión en la época de la gran espiritualidad: esa época con la que soñaron Kandinsky y los teósofos pero que nunca llegó.

\section{Wittgenstein y la religión como sometimiento a Dios}

Los diarios y biografías de Wittgenstein ofrecen múltiples ejemplos de la gran importancia que este filósofo vienés dio a lo largo de su vida al hecho de comportarse decentemente. Para Wittgenstein la decencia está relacionada, ante todo, con conocerse a uno mismo y hacer que dicho conocimiento guíe la propia vida. Sin embargo, este autoconocimiento no puede ser alcanzado en la superficie de la vida -por ejemplo, en la vida del hombre vanidoso cuya imagen de sí mismo suele ser la imagen de cómo le gustaría ser realmente o de cómo le gustaría ser visto por los demás-. Lejos de tal cosa, el profundo autoconocimiento que persigue Wittgenstein exige abandonar la vida superficial y descender al fondo de uno mismo: al abismo en que uno puede conocer quién

[33] Kandinsky, W.: De lo espiritual cit., p. 56.

[34] Steiner, R.: "Wie erlangt man" cit., pp. 13-28.

[35] Steiner,R.:Theosophie:EinführunginübersinnlicheWelterkenntnisundMenschenbestimmung. Berlin: C. A. Schwetschke und Sohn, 1904, p. 101. En esa misma página Steiner añadió que a toda percepción de un color o una luz le corresponde un «tono espiritual».

[36] Kandinsky, W.: De lo espiritual cit., pp. 72-76, 122.

[37] Ibídem, p. 72.

THÉMATA. Revista de Filosofía, Nº49 enero-junio (2014) pp.: 33-50

doi: 10.12795/themata.2014.i49.02 
es realmente. Ahora bien, descender al propio abismo resulta insoportable a menos que se acepte con la mayor humildad ser lo que se es $^{38}$. Pero si se es capaz de descender al fondo de ese abismo y mantenerse en él, el autoconocimiento que se obtiene permite alcanzar una profundidad que no se puede lograr con el mero talento. En palabras de Wittgenstein: «Cuanto menos se conoce y se entiende uno a sí mismo, menos grande es, por grande que pueda ser su talento» ${ }^{39}$. Para Wittgenstein el gran hombre es aquel que además de saber quién -o qué- es realmente, lo acepta: de hecho, Wittgenstein está convencido de que sólo un hombre grande puede llevar a cabo una gran obra, ya que la profundidad de cualquier obra depende de la profundidad en la que se halle su autor ${ }^{40}$. Por eso depende la grandeza de lo que se escribe de todo lo demás que se haga y escriba ${ }^{41}$. Esta grandeza se percibe en el estilo, de modo que sólo quien tenga el coraje necesario para conocerse a sí mismo escribirá algo auténtico, mostrará un estilo propio y será profundo en su escritura ${ }^{42}$. Wittgenstein presupone que cada hombre tiene su propio estilo, el cual constituye una expresión de la naturaleza única e intransferible de cada individuo. Así, el estilo carente de autenticidad es el que surge, por ejemplo, cuando se imita a otro autor o cuando simplemente no se ha hecho un esfuerzo suficiente para conocer la propia naturaleza ${ }^{43}$ : en tal caso, el estilo que aparece es superficial $\mathrm{y}$, por tanto, falso.

¿Pero en qué consiste exactamente esta «naturaleza» de la que habla Wittgenstein? En palabras del pensador vienés, esta naturaleza se podría entender como un "aparato" que permite hacer determinadas cosas -hasta un cierto límite o medida- y no otras ${ }^{44}$. A tenor de lo dicho, Wittgenstein toma la

[38] De ahí que Wittgenstein escriba: «Autoconocimiento \& humildad es lo mismo» (WiTTGENSTEIN, L.: Movimientos del pensar cit., §97).

[39] Wittgenstein, L.: «Vermischte Bemerkungen» en WitTGenstein, L.: Über Gewißheit (Werkausgabe Band 8). Frankfurt: Suhrkamp, 1984, p. 516. Se trata de una observación del año 1946 que no aparece traducida en la versión en castellano titulada Cultura y valor.

[40] Cfr. Wittgenstein, L.: Cultura y valor cit., § 279.

[41] Ibídem, § 380.

[42] Wittgenstein, L.: Wittgenstein's Nachlass: The Bergen Electronic Edition. Text and Facsimile Edition. Oxford: Oxford University Press, 2000, MS (=Manuscrito) 120, pp. 72-73. Wittgenstein señala también que él mismo comete a menudo el error de creer que puede escribirse todo lo que se piensa, cuando en realidad sólo puede escribirse «lo que surge en nosotros en forma de escritura»: así, todo lo demás resulta cómico, como si fuera basura o algo que habría que hacer desaparecer (Wittgenstein, L.: Movimientos del pensar cit., § 27).

[43] No ha de extrañar, por tanto, que según Wittgenstein alguien sea ya suficientemente original cuando no miente, o sea, cuando no quiere ser lo que no es (WitTGEnstein, L.: Cultura y valor cit., $\S \S 346-347)$. Además, este énfasis en la autenticidad de cada individuo le lleva a afirmar que en el ámbito de lo profundo - es decir, en el abismo de lo religioso- no hay revolucionarios de masas: «Revolucionario será aquel que pueda revolucionarse a sí mismo» (Ibídem, § 260).

[44] Ibídem, § 336. A modo de ejemplo, Wittgenstein señala que él no puede escribir versos pero sí prosa, aunque sólo hasta un límite muy determinado.

THÉMATA. Revista de Filosofía, No 49 enero-junio (2014) pp.: 33-50

doi: 10.12795/themata.2014.i49.02 
propia naturaleza como algo dado e invariable que no sólo determina el grado de perfección que se puede alcanzar en cierto ámbito, sino que además estipula, por así decir, el tipo de persona que realmente se es más allá de toda convención o fingimiento. Wittgenstein se propuso escribir una autobiografía que le ayudara a conocer su propia naturaleza y a dejar que dicho conocimiento guiara su vida ${ }^{45}$. Como bien dijo en su momento Rush Rhees, el deber de seguir la propia naturaleza, sumado al hecho de que la naturaleza de cada hombre es única e intransferible, tiene como consecuencia que lo que es correcto -o mejor dicho, imperativo- para un hombre tal vez no lo sea para otro ${ }^{46}$.

No obstante, la experiencia de descender al propio abismo, tal y como la planteaba Wittgenstein, constituía un arma de doble filo. Por un lado, estaba totalmente convencido de que este descenso, o sea, la religión, era la única forma de eliminar la vanidad que le impedía reconocer y aceptar lo que realmente era ${ }^{47}$. Pero por otro lado, señaló que el hombre religioso se considera a sí mismo «miserable» ${ }^{48}$. Pues en su opinión, conocerse a sí mismo conlleva «mirar al perfecto» y humillarse totalmente ante él, ya que sólo así se puede sostener su mirada ${ }^{49}$. A pesar de todo, Wittgenstein creía que un abismo no tiene por qué ser necesariamente algo terrible ${ }^{50}$, pues no en vano cabe la posibilidad de intentar mantenerse firme en su fondo, sin permitir ser superado por el miedo ${ }^{51}$. Sin embargo, el hecho de que alguien pueda mantener en cierta ocasión la mirada del perfecto no garantiza que será capaz de mantenerla indefinidamente. Pues la humillación ante la mirada del perfecto es tan avasalladora que resulta muy difícil no acabar desviando la vista -e incluso no rebelarse de un modo u otro contra Dios-. Así que si se quiere permanecer en lo religioso, hay que luchar ${ }^{52}$ : naturalmente, no se trata de luchar contra Dios, sino de luchar contra uno mismo precisamente para abandonarse a Dios. Wittgenstein describe así la vulnerabilidad del sujeto en semejante situación:

Estar solo con uno mismo - o con Dios, ¿no es como estar solo con una fiera? En cualquier momento puede atacarte. - Pero i¿no sucede eso precisamente porque no debes huir?! ¡¿No es eso, por así decirlo, lo magnífico?! (... $)^{53}$

[45] Este afán de dejarse guiar única y exclusivamente por su naturaleza le llevó a tratar de evitar a toda costa ser guiado por el ejemplo (Ibídem, § 227) o la opinión de otros (Ibídem, § 8).

[46] Rhees, R.: «Posdata» en Rhees, R. (comp.): Recuerdos de Wittgenstein. México: FCE, 1989, p. 294.

[47] Wittgenstein, L.: Cultura y valor cit., § 271.

[48] Ibídem, §501.

[49] Wittgenstein, L.: Movimientos del pensar cit., §§ 213-214.

[50] Ibídem, § 200.

[51] Cfr. Ibídem, §§ 154, 186-187.

[52] Wittgenstein, L.: «Vermischte Bemerkungen» cit., p. 572.

[53] Wittgenstein, L.: Movimientos del pensar cit., § 238.

THÉMATA. Revista de Filosofía, Nº 49 enero-junio (2014) pp.: 33-50

doi: 10.12795/themata.2014.i49.02 
La fiera que se halla en el fondo del abismo sólo puede ser amansada humillándose ante ella. Pero es precisamente esta humillación la que permite alcanzar el más profundo autoconocimiento y, por extensión, las grandes obras de la humanidad. Repárese en la similitud que presenta el párrafo que reproduzco a continuación con el que acabo de transcribir:

En todo gran arte hay un animal SALVAJE domado. (...) Todo gran arte tiene como fundamento los instintos primitivos del hombre. No son la melodía (como, por ejemplo, en Wagner), sino aquello que da su profundidad y fuerza a la melodía. ${ }^{54}$

El regreso al abismo resulta especialmente penoso cuando ya se conoce a la fiera que espera allí abajo, pues en dicho abismo sólo se puede evitar la locura, la destrucción y la infelicidad mientras uno se sienta totalmente miserable y humillado ante Dios. Prueba de ello es que Wittgenstein reconoció que necesitaba "un corazón puro" para ser capaz de mantener la mirada del perfecto ${ }^{55}$. Cuando Wittgenstein escribe esto, en marzo de 1937, reconoce que por aquel entonces estaba volcado en la lectura de Kierkegaard ${ }^{56}$. Es verdad que Wittgenstein no señala explícitamente qué obra u obras de Kierkegaard estaba leyendo; pero teniendo en cuenta su interés en la expresión «un corazón puro", podríamos tomar como referencia para entender estas reflexiones de Wittgenstein el primero de los veinte Discursos edificantes de Kierkegaard: concretamente, me refiero al discurso La pureza de corazón es querer una sola cosa. En esta obra se lee que cuando un hombre sólo quiere una cosa, lo único que puede querer es el Bien -o sea, Dios o lo Eterno-, ya que cualquier otro objeto carece de unidad. Según Kierkegaard, el que verdaderamente desea el Bien debe querer hacerlo todo con miras al Bien, por lo que debe estar dispuesto a sufrirlo todo por la misma causa ${ }^{57}$. Kierkegaard advierte también que una de las manifestaciones características del indeciso, aquel que además del Bien quiere alguna otra cosa, se refleja en la fórmula: "Carezco de fuerza para arriesgarme a todo» ${ }^{58}$. Por su parte, Wittgenstein confiesa que no es capaz de renunciar al disfrute, por lo que sufre el lacerante dolor del abandono ${ }^{59}$. Este dolor del abandono es propio del indeciso; en cambio, el que realmente quiere lo Bueno no tiene por qué estar preocupado ${ }^{60}$, ya que la redención a través del compromiso con lo Eterno no es ninguna fuente de sufrimiento, sino una

[54] Wittgenstein, L.: Cultura y valor cit., § 203.

[55] Cfr. Wittgenstein, L.: Movimientos del pensar cit., §§ 216-217.

[56] Ibídem, $\S 166,176$. Efectivamente, en aquella época eran frecuentes las alusiones a Kierkegaard en los diarios de Wittgenstein (cfr. Ibídem, §§ 75, 102, 122-123, 136, 204, 241).

[57] Kierkegaard, S.: La pureza de corazón es querer una sola cosa. Buenos Aires: Ediciones La Aurora, 1979, p. 137.

[58] Ibídem, p. 145.

[59] Wittgenstein, L.: Movimientos del pensar cit., § 119.

[60] Kierkegaard, S.: La pureza cit., p. 163.

THÉMATA. Revista de Filosofía, No 49 enero-junio (2014) pp.: 33-50

doi: 10.12795/themata.2014.i49.02 
«liberación» ${ }^{61}$. Por tanto, el que verdaderamente confía en Dios es entusiasta ${ }^{62}$ y avanza con paso firme. Pero Kierkegaard advierte que la inteligencia es un amigo traicionero, en tanto que sólo el compromiso es merecedor de confianza ${ }^{63}$. El que verdaderamente quiere el Bien usa la inteligencia para prevenir todas las posibles evasiones del compromiso, o lo que es lo mismo, para aferrarse a dicho compromiso ${ }^{64}$. El propio Wittgenstein usa a menudo la inteligencia para evadir su compromiso con Dios y la verdad ${ }^{65}$, aunque él mismo reconoce que aquél que descansa en Dios descansa en la verdad: y es precisamente ese individuo, el que descansa en la verdad, el único que puede decirla ${ }^{66}$. Tal y como apuntó Ilse Somavilla, sólo con esa confrontación con lo religioso puede conseguir el artista que sus obras conmuevan: pues una obra de arte sólo puede ser creíble y veraz al surgir de los sufrimientos del espíritu que aparecen cuando se toma conciencia de la seriedad de la vida y la muerte ${ }^{67}$. De hecho, Wittgenstein mantiene que también para filosofar hay que descender al viejo caos y sentirse a gusto en él ${ }^{68}$.

Lo dicho hasta el momento no aclara completamente cómo se reflejaría en la propia vida la humillación experimentada en el fondo del abismo. Pero Wittgenstein aclara esta cuestión cuando señala que la vida suprema es aquella cuyos actos están siempre guiados por inspiraciones ${ }^{69}$. Estas «inspiraciones» a las que se refiere Wittgenstein son las exigencias de Dios que, si no se satisfacen, pueden dar lugar a la locura y la infelicidad ${ }^{70}$. No seguir una inspiración sería como volverle la espalda a Dios. Además, estas inspiraciones son expresiones de la propia naturaleza de cada cual: tal y como Wittgenstein manifiesta a menudo, las inspiraciones proceden del corazón ${ }^{71}$. Así pues, la vida suprema

[61] Ibídem, p. 196.

[62] Ibídem, p. 164.

[63] Ibídem, p. 191.

[64] Ibídem, p. 157.

[65] Cfr. Wittgenstein, L.: Movimientos del pensar cit., §§ 130, 182.

[66] Wittgenstein, L.: Cultura y valor cit., § 187.

[67] Somavilla, I.: «Luz y sombra: Reflexiones sobre los textos de Wittgenstein» en WitTGEnstein, L.: Luz y sombra. Una vivencia(-sueño) nocturna y un fragmento epistolar. Valencia: Pre-Textos, 2006, pp. 97, 99.

[68] Wittgenstein, L.: Cultura y valor cit., § 379.

[69] Wittgenstein, L.: Movimientos del pensar cit., §§ 194-195.

[70] Ibídem, § 174. En este mismo fragmento Wittgenstein vuelve a reconocer su debilidad cuando dice: «Me gustaría ser profundo; - \& iisin embargo me arredro ante el abismo que hay en el corazón humano!!».

[71] Al hablar de "cómo debería ser la vida», Kierkegaard señala que el que verdaderamente quiere una sola cosa es «un alma sencilla, que responde feliz a los impulsos de su corazón» (KIERKEGAARD, S.: La pureza cit., p. 65). Algunos ejemplos en los que Wittgenstein se plantea actuar en función de lo que le sale del corazón se hallan en Wittgenstein, L.: Movimientos del pensar cit., §§ 89, 179, 218-219, 225, 231.

THÉMATA. Revista de Filosofía, N 49 enero-junio (2014) pp.: 33-50

doi: 10.12795/themata.2014.i49.02 
es aquella en la que todos los actos se guían por inspiraciones; pero debe tratarse de una vida auténtica en la que realmente se haga y diga con entusiasmo -es decir, con profundo y religioso entusiasmo- lo que salga del corazón. Pues si se quisiera vivir una vida dirigida por inspiraciones con el fin de conseguir que la permanencia en el abismo se haga soportable, se trataría de una vida falsa ${ }^{72}$.

\section{A modo de conclusión}

A pesar de su brevedad, esta exposición permite entrever ya marcadas similitudes en las visiones que Kandinsky y Wittgenstein tenían de la conmoción artística. A continuación describiré algunas de esas similitudes, lo cual me permitirá crear un marco común a partir del cual será posible señalar con nitidez las profundas diferencias que subyacen en la concepción que ambos personajes tenían del espíritu y, por extensión, de la conmoción artística. Comencemos, pues, con las similitudes.

Para empezar, podríamos decir que el objetivo último de Kandinsky era indicarnos cómo recuperar a través del arte la armonía perdida con un orden cósmico del que hemos dejado de ser partícipes. Este orden cósmico se refleja o manifiesta en la sonoridad interna que se desprende de todo lo que nos rodea: palabras, imágenes, objetos... Todo posee una sonoridad interna que sólo podrá ser captada espiritualmente cuando desarrollemos nuestra sensibilidad liberándola de toda influencia de índole intelectual o práctico-utilitaria. Ni que decir tiene que la idea de participar en el espíritu no le resultaba en absoluto ajena a Wittgenstein ${ }^{73}$. En este sentido, Vicente Sanfélix matizó que Wittgenstein entendía la filosofía como una «respiración espiritual, una participación en el espíritu» que a sus ojos convertía la filosofía en una actividad religiosa tanto en su objetivo como en su misma génesis ${ }^{74}$.

Ni Kandinsky ni Wittgenstein eran ajenos al profundo carácter místico que entraña el proceso de creación artística. Así, Kandinsky señaló que la captación de lo espiritual era inefable, pues el lenguaje con el que la naturaleza ejerce su fuerza insuperable sobre nosotros es inimitable y sólo puede ser captado a ni-

[72] En palabras de Kierkegaard, esta vida falsa sería la vida propia del indeciso, del que sólo quiere lo Bueno por temor al castigo, de modo que estaría lejos de querer verdaderamente lo Bueno. Pues el castigo es un Bien no cuando es temido, sino cuando se lo recibe con gratitud (KIERKEGAARD, S.: La pureza cit., p. 105).

[73] Ver por ejemplo Wittgenstein, L.: Movimientos del pensar cit., § 122. No obstante, la mayoría de referencias explícitas por parte de Wittgenstein al espíritu y al lema tolstoiano «El hombre es impotente en la carne, pero libre gracias al espíritu» se hallan en textos tan tempranos como sus diarios de guerra escritos entre 1914 y 1916. Ver Wittgenstein, L.: Diarios secretos. Madrid: Alianza, 1991, pp. 53, 55, 59, 67, 111, 125, etc.

[74] Sanfélix, V.: «Una filosofía del espíritu. Wittgenstein y la cuestión judía» en RodríguEz, M. (ed.): La mente en sus máscaras. Ensayos de filosofía de la psicología. Madrid: Biblioteca Nueva, 2005, p. 297.

THÉMATA. Revista de Filosofía, No 49 enero-junio (2014) pp.: 33-50 doi: 10.12795/themata.2014.i49.02 
vel meramente intuitivo como sonoridad interna ${ }^{75}$. A lo sumo se puede explicar o criticar la forma, pero eso no bastará para entender el espíritu de la obra porque su contenido sólo es accesible indirectamente, sintiéndolo ${ }^{76}$. De forma similar, Wittgenstein da a entender que la captación del espíritu característica del gran hombre se muestra en el estilo: y si bien hemos visto que Wittgenstein se refería al estilo de la escritura, considero que también podemos aplicar sus reflexiones sobre el estilo del gran hombre a otras modalidades expresivas como la pintura o la música ${ }^{77}$. Para justificar esta opinión me gustaría recordar que, cuando Wittgenstein interpreta la conocida frase de Georges L. L. Buffon «le style c'est l'home même» afirmando sobre ella que su verdadero significado es "que el estilo es la imagen del hombre» ${ }^{78}$, no se refiere a una modalidad expresiva en concreto. Lejos de tal cosa, su intención es poner el énfasis en que la imagen del hombre - es decir, la imagen de la naturaleza de cada sujeto- que se desprende del estilo no admite diversas interpretaciones, sino que ha de ser tomada tal cual $\mathrm{es}^{79}$. Mientras que para Wittgenstein el estilo es la imagen del hombre -o lo que es lo mismo, el reflejo de su naturaleza-, Kandinsky mantiene que la forma lleva el sello de la personalidad o espíritu de cada artista ${ }^{80}$. Ahora bien, Kandinsky no parte, como hace Wittgenstein, del presupuesto de que cada hombre tiene una naturaleza distinta o una especie de "aparato» que le permite hacer determinadas cosas en mayor o menor grado pero no otras: lejos de tal cosa, Kandinsky se limita a señalar que cada persona tiene distintos contenidos que expresar ${ }^{81}$. El artista sabe que tiene algún contenido que expresar cuando siente la necesidad interior de crear una obra de arte: en ese caso, Kandinsky recomienda que el artista evite pensar cuando se halle ante el caballete ${ }^{82}$, pues una actitud intelectual lleva necesariamente a la alienación de la sensibilidad que resulta de todo punto

[75] Ver nota 11.

[76] Kandinsky, W.: «De la comprensión del arte» en Kandinsky, W.: La gramática de la creación. El futuro de la pintura. Barcelona: Paidós, 1996, p. 40.

[77] Partiendo de que Wittgenstein se propone hacer sólo aquello que realmente le salga del corazón, cabe pensar que así como rechaza toda escritura que no surja en él en forma de escritura (ver nota 42), igualmente despreciaría toda pieza de música que no surja de él como tal, toda pintura que no surja de él como pintura, etc. Desde este punto de vista, de la conocida expresión bíblica "[d] ecid lo que el espíritu os inspire» (Mateo 10,19) se seguiría que la modalidad expresiva también sería inspirada por el propio espíritu.

[78] Wittgenstein, L.: Cultura y valor cit., § 450.

[79] En palabras de Wittgenstein, «[n]o juzgamos imágenes, sino mediante imágenes. No son ellas lo que investigamos, sino, mediante ellas, algo diferente» (Wittgenstein. L.: Observaciones sobre los fundamentos de la matemática. Madrid: Alianza, 1987, p. 191).

[80] Kandinsky, W.: «Sobre la cuestión» cit., p. 137.

[81] Ibídem, p. 136.

[82] Kandinsky, W.: "El valor de una obra concreta» en Kandinsky, W.: La gramática de la creación. El futuro de la pintura. Barcelona: Paidós, 1996, p. 150.

THÉMATA. Revista de Filosofía, Nº49 enero-junio (2014) pp.: 33-50

doi: 10.12795/themata.2014.i49.02 
fundamental para crear una obra de $\operatorname{arte}^{83}$. Por su parte, Wittgenstein también tiene presente que la inteligencia no es compatible con el querer hacer sólo lo que salga del corazón, ya que seguir una inspiración requiere llevarla a cabo con entusiasmo -sin hacer cálculos o previsiones sobre las consecuencias que ello tendrá- porque constituye una exigencia de Dios.

A tenor de lo dicho hasta el momento, podría parecer que entre las concepciones que Kandinsky y Wittgenstein tenían del proceso de creación artística priman de forma abrumadora las similitudes. Sin embargo, existen también profundas diferencias que deben ser tenidas en cuenta. Una diferencia palpable es que Kandinsky persigue despertarnos a una nueva era ofreciendo el arte como un medio universal de curación para el alma, en tanto que Wittgenstein no cree en los revolucionarios de masas porque a su juicio las verdaderas revoluciones son las que tienen lugar a nivel individual ${ }^{84}$ : de ahí que diga, por ejemplo, que cuando el hombre auténtico -o su naturaleza- permanece aún oculto, no está oculto ante otros, sino ante sí mismo ${ }^{85}$.

Otra diferencia importante es la que concierne a su concepción del autoconocimiento. A pesar de que ambos entonan con aprobación el lema socrático "conócete a ti mismo»" ${ }^{86}$, en el caso de Wittgenstein el autoconocimiento o conocimiento de la propia naturaleza muestra qué es imperativo o correcto para cada cual, mas Kandinsky simplemente recomienda al artista que se eduque y ahonde en su propia alma "para que su talento externo tenga algo que vestir»" ${ }^{87}$. Mientras que Wittgenstein trata de aclarar cuál es la vida justa o suprema desde el punto de vista ético, Kandinsky pretende refinar el alma: para lograr tal cosa no pretende pintar la música o los estados del alma, sino simplemente pintar cuadros que sean "sentidos» por otros, aunque se trate de un grupo reducido ${ }^{88}$.

Por último, la diferencia más importante radica en la actitud misma que el artista debe mostrar ante la génesis de la obra de arte. Según Kandinsky, el artista es esclavo de la voz o necesidad interior que guía su labor artística89; pero si esa voz se torna indiferente en exceso, el artista debe dejar a un lado sus pinceles y esperar ${ }^{90}$. De hecho, su esposa Nina comentó que Kandinsky no se forzaba a dibujar cuando no sentía necesidad interior alguna ${ }^{91}$. En cambio, Wittgenstein considera la auténtica obra de arte como el resultado de un salto

[83] Kandinsky, W.: Cursos de la Bauhaus cit., pp. 66-67.

[84] Ver nota 42. En este punto se aprecia la clara influencia que sobre Wittgenstein ejercieron autores como Otto Weininger.

[85] Cfr. Wittgenstein, L.: Movimientos del pensar cit., § 97.

[86] Kandinsky, W.: De lo espiritual cit., p. 49; WitTgenstein, L.: Movimientos del pensar cit., § 102.

[87] Kandinsky, W.: De lo espiritual cit., p. 115.

[88] Kandinsky, W.: «Conferencia de Colonia» cit., p. 58.

[89] Ibídem, p. 59.

[90] Kandinsky, W.: «El arte de hoy» cit., p. 123.

[91] Kandinsky, N.: Kandinsky y yo. Barcelona: Parsifal, 1990, p. 40.

THÉMATA. Revista de Filosofía, No 49 enero-junio (2014) pp.: 33-50

doi: 10.12795/themata.2014.i49.02 
a lo incierto, al abismo, allí donde espera la fiera que no admite otra actitud que la humillación y el sometimiento incondicional. Frente a la pasividad proclamada por Kandinsky, según el cual el artista debe esperar a que las musas tengan a bien visitarle, Wittgenstein piensa que el gran hombre -y por tanto, también el gran artista- es aquel que ya ha tenido el extraordinario coraje e iniciativa de saltar al fondo de su propio abismo. El estilo de este hombre refleja fielmente su naturaleza, por lo que se trata de un estilo verdadero: un estilo propio de quien vive en la verdad, en el fondo del abismo en el que sólo el puro de corazón puede mantenerse tomando toda exigencia o inspiración como una dádiva, con entusiasmo, por muy dolorosa que dicha exigencia pudiera resultar para ese mismo sujeto en un momento de indecisión o impureza de corazón. Se podría decir que el artista aparece para Kandinsky como el portavoz que el espíritu elige de cuando en cuando para expresarse, en tanto que Wittgenstein exige que el artista viva en el espíritu. Dicho de otro modo: desde el punto de vista de Kandinsky, el artista debe materializar en el lienzo, como si de una especie de eco se tratara, el contenido ligado a la necesidad interior que sienta en un momento dado, en tanto que Wittgenstein exige que el auténtico artista sea $y a$ un hombre grande que viva en la verdad. Pues sólo aquel que resida en la verdad podrá transmitirla. 


\section{Referencias bibliográficas:}

Blavatsky, H. P.: The Key to Theosophy. London: The Theosophical Publishing Company, 1889.

Eaves, A. O.: Die Kräfte der Farben: der Weg zur Gesundheit. Berlin: Georgi, 1906.

Kandinsky, N.: Kandinsky y yo. Barcelona: Parsifal, 1990.

Kandinsky, W.: Cursos de la Bauhaus. Madrid: Alianza, 1991.

Kandinsky, W.: De lo espiritual en el arte. Barcelona: Labor, 1995.

Kandinsky, W.: Punto y línea sobre el plano. Contribución al análisis de los elementos pictóricos. Barcelona: Labor, 1995.

Kandinsky, W. y Marc, F. (eds.). El jinete azul. Barcelona: Paidós, 1989.

Kandinsky, W.: "Sobre la cuestión de la forma» en Kandinsky, W. y Marc, F. (eds.): El jinete azul. Barcelona: Paidós, 1989, p. 131-193.

Kandinsky, W.: «De la comprensión del arte» en Kandinsky, W.: La gramática de la creación. El futuro de la pintura. Barcelona: Paidós, 1996, pp. 35-40.

Kandinsky, W.: "Conferencia de Colonia» en Kandinsky, W.: La gramática de la creación. El futuro de la pintura. Barcelona: Paidós, 1996, p. 49-59.

Kandinsky, W.: "El arte de hoy está más vivo que nunca» en Kandinsky, W.: La gramática de la creación. El futuro de la pintura. Barcelona: Paidós, 1996, p. 117-125.

Kandinsky, W.: «El valor de una obra concreta» en Kandinsky, W.: La gramática de la creación. El futuro de la pintura. Barcelona: Paidós, 1996, pp. 139-150.

Kierkegaard, S.: La pureza de corazón es querer una sola cosa. Buenos Aires: Ediciones La Aurora, 1979.

Rhees, R.: «Posdata» en Rhees, R. (comp.): Recuerdos de Wittgenstein. México: FCE, 1989, pp. 271-325.

Ringbom, S.: The Sounding Cosmos. A Study in the Spiritualism of Kandinsky and the Genesis of Abstract Painting. Åbo: Åbo Akademi, 1970.

Sanfélix, V.: «Una filosofía del espíritu. Wittgenstein y la cuestión judía» en Rodríguez, M. (ed.): La mente en sus máscaras. Ensayos de filosofía de la psicología. Madrid: Biblioteca Nueva, 2005, pp. 290-305.

Somavilla, I.: «Luz y sombra: Reflexiones sobre los textos de Wittgenstein» en Wittgenstein, L.: Luz y sombra. Una vivencia(-sueño) nocturna y un fragmento epistolar. Valencia: Pre-Textos, 2006, pp. 61-102.

Steiner, R.: "Wie erlangt man Erkenntnisse der höheren Welten?" en LuciferGnosis, 1904, pp. 13-51.

Steiner, R.: Theosophie: Einführung in übersinnliche Welterkenntnis und Menschenbestimmung. Berlin: C. A. Schwetschke und Sohn, 1904.

Wittgenstein, L.: «Vermischte Bemerkungen» en Wittgenstein, L.: Über Gewißheit (Werkausgabe Band 8). Frankfurt: Suhrkamp, 1984, pp. 445-575. 
Wittgenstein, L.: Observaciones sobre los fundamentos de la matemática. Madrid: Alianza, 1987.

Wittgenstein, L.: Diarios secretos. Madrid: Alianza, 1991.

Wittgenstein, L.: Tractatus logico-philosophicus. Barcelona: Altaya, 1994.

Wittgenstein, L.: Lecciones y conversaciones sobre estética, psicología y creencia religiosa. Barcelona: Paidós, 1996.

Wittgenstein, L.: Cultura y valor. Aforismos. Madrid: Austral, 1996.

Wittgenstein, L.: Movimientos del pensar. Diarios 1930-1932/1936-1937. Valencia: Pre-Textos, 2000.

Wittgenstein, L.: Wittgenstein's Nachlass: The Bergen Electronic Edition. Text and Facsimile Edition. Oxford: Oxford University Press, 2000. 